Zheng et al., Afr J Tradit Complement Altern Med. (2013) 10(1):9-14

http://dx.doi.org/10.4314/ajtcam.v10i1.2

\title{
EFFECTS OF A CHINESE MEDICINAL PLANT RADIX ASTRAGALI ON THE OVARIECTOMIZED FEMALE RATS
}

\author{
Yan Zheng ${ }^{1}$, Yue $\mathrm{Jin}^{1}$, Hai-Bin $\mathrm{Zhu}^{1}$, Shao-Ting $\mathrm{Xu}^{1}$, Ya-Xian Xia ${ }^{1}$, Yue Huang ${ }^{2 *}$ \\ ${ }^{1}$ Department of Gynecology, The First Affiliated Hospital, Medical College of Zhejiang University, 79 \\ Qingchun Road, Hangzhou, 310003, P.R. China. ${ }^{2}$ Department of Orthopaedic Surgery, Sir Run Run \\ Shaw Hospital, Medical College of Zhejiang University, 3 East Qingchun Road, Hangzhou, 310016 , \\ P.R. China. \\ *Email: drhuangyue@126.com
}

\begin{abstract}
Perimenopausal syndrome occurs during the transition to menopause. Complementary and alternative medicine, especially Chinese medicinal plants, has manifested significant effects in alleviating perimenopausal symptoms. However, little research has been focused on the effects of Chinese medicinal plant on the immune function of the perimenopausal women. The present study aimed to explore the effects of Radix Astragali (RA) on the sex hormone levels and the interleukins of the ovariectomized female rats. 24 female Sprague-Dawley (SD) rats were randomly divided into model control group (MOD group), sham-operation group (SHAM group), RA group and estrogen group (EST group). After all the treatment ended, the serum levels of estradiol (E2), follicle stimulating hormone (FSH), luteinizing hormone (LH), interleukin-2 (IL-2), and interleukin-8 (IL-8) were measured using enzyme-linked immune-sorbent assay (ELISA) and the uterus was removed and weighed after blood exsanguinations immediately. In the MOD group, the serum levels of E2 were significantly lower, and the serum levels of FSH and LH were markedly higher than those of the RA group, EST group and SHAM group $(\mathrm{P}<0.05)$. In the RA group, the serum levels of E2 were significantly lower, and the serum levels of FSH were markedly higher than those of the SHAM group and EST group, respectively. In the MOD group, the serum levels of IL-2 and IL-8 were significantly lower than those of the RA group, EST group and SHAM group $(\mathrm{P}<0.05)$, and no marked differences existed among RA group, EST group and SHAM group in the serum levels of IL-2 and IL-8 (P>0.05). The uterine weight of the rats in the RA group, EST group and SHAM group were significantly higher than those of the rats in MOD group $(\mathrm{P}<0.05)$. There were no marked differences among the rats from RA group, EST group and SHAM group on the uterine weight $(\mathrm{P}>0.05)$. It is concluded that RA can significantly improve the immune functions of the ovariectomized female rats, although it cannot change the sex hormones levels as significantly as estrogen.
\end{abstract}

Keywords: Perimenopausal syndrome, Radix Astragali, ovariectomized rats

\section{Introduction}

As we know, perimenopausal syndrome occurs during the transition to menopause, which is often accompanied by hot flashes and degenerative processes such as arteriosclerosis and atrophic changes of the skin and these symptoms suggest an acceleration of aging triggered by estrogen lack (Miquel et al., 2006). Hormone replacement therapy (HRT) has been considered as the most suitable treatment for the above symptoms and processes (Roberts, 2012). However, some previous clinical trials using different estrogen formulations, doses of raloxifene combined with estrogens failed to show the certified effects of HRT on the quality of life in the menopausal women (Carneiro et al., 2012). HRT is even contraindicated for the women with a history of breast cancer (Duijts et al., 2009). Complementary and alternative medicine, especially Chinese medicinal plants, have manifested significant effects in alleviating perimenopausal symptoms (Borrelli and Ernst, 2010; Kessel and Kronenberg, 2004; Kronenberg and Fugh-Berman, 2002; Lloyd and Hornsby, 2009; Seidl and Stewart, 1998; Shou et al., 2011).

As we know, cytokines are biologically active macromolecules of protein structure (Martin et al., 2006), and HRT was found to improve the balance of Th1/Th2 cytokines mainly through estrogen acting in T lymphocytes (Xia et al., 2009). The perimenopausal women present a totally different alteration in serum cytokine profile of interleukins from the fertile women (Cioffi et al., 2002). In a study to explore the effects of HRT on T-cell function in postmenopausal women, the researchers found that HRT improved the aberration of Th1/Th2 balance that is implicated in an inadequate immune response and pathological conditions (Kamada et al., 2001). However, little research has been focused on the effects of Chinese medicinal plant on the immune function of the perimenopausal women. Radix Astragali (RA Chinese name: Huang Qi, family:), it is the root portion of Astragalus membranaceus or Astragalus propinquus, belonging to the legume family Fabaceae, subfamily Faboideae. RA is one the most commonly used medicinal plants involved in the female reproductive system (Mazaro-Costa et al., 2010). RA has been reported to have eminently positive effects on the immune system (WHO). The present study aimed to explore the effects of RA on the sex hormone levels and the interleukins of the ovariectomized female rats. 
Zheng et al., Afr J Tradit Complement Altern Med. (2013) 10(1):9-14

http://dx.doi.org/10.4314/ajtcam.v10i1.2

\section{Materials and methods Animals}

32 ten-week-old female Sprague-Dawley (SD) rats (weighing 220 $\pm 20 \mathrm{~g}$ ) were provided by the Laboratory Animal Center of Zhejiang Chinese Medicine University (Hangzhou, China). The animals were kept in a room under a $12 \mathrm{~h}$ light-12h dark cycle and environmentally controlled conditions of $22 \pm 2^{\circ} \mathrm{C}$. All the animals were acclimatized one week before the experiment. The research was carried out according to the National Research Council's protocol for the care and use of laboratory animals. Eight rats were randomly taken as the sham-operation group (SHAM group) and the other 24 rats were bilaterally ovariectomized as described by EI-Bakri et al (El-Bakri et al., 2004). All of the 32 rats were anesthetized with an intraperitoneal (i.p.) injection of sodium pentobarbital $(50 \mathrm{mg} / \mathrm{kg})$. The vaginal smear was taken from each of the 32 rats once daily for 4 consecutive days from the $3^{\text {rd }}$ day after the ovariectomized operation. Six rats with classic estrous cycles in the SHAM group were included in the study. The successfully ovariectomized rats, confirmed by predominantly leukocytes with few epithelial cells in vaginal smears over at least 4 days, were randomly divided into RA group, estrogen group (EST group), and model control group (MOD group) ( $\mathrm{n}=6$ in each group).

\section{The preparation of plant materials}

RA was provided and identified by Zhejiang Chinese Medicine University (Hangzhou, China). RA was extracted by refluxing per $25 \mathrm{~g}$ with $250 \mathrm{ml}$ of water for $60 \mathrm{~min}$ followed by filtration. The same extraction procedures were repeated once. The obtained solution was combined and condensed to a concentration of $1 \mathrm{~g} / \mathrm{ml}$, which was then freeze dried and get extract of RA.

\section{Group and administration}

The rats in RA group were orally administrated the extracts of RA at $71 \mathrm{mg} / \mathrm{kg}$ once daily for 28 consecutive days. The rats in EST group were orally administrated estradiol valerate tablet (provide by Bayer AG, Germany) at $1.2 \mathrm{mg} / \mathrm{kg}$ once daily for 28 consecutive days. The rats in MOD group and SHAM group were orally administrated saline at $8 \mathrm{ml} / \mathrm{kg}$ once daily for 28 consecutive days. On the day following the final administration, the serum and uterus samples were taken after the rats were anesthetized with diethyl ether. The serum obtained was stored at $-80{ }^{\circ} \mathrm{C}$ until assay. The serum levels of estradiol (E2), follicle stimulating hormone (FSH), luteinizing hormone (LH), interleukin-2 (IL-2), and interleukin-8 (IL-8) were measured using enzyme-linked immune-sorbent assay (ELISA, R\&D Systems, MN, USA). All the measurements were carried out in duplicate and were conducted according to the manufacturer's instruction. The uterus was also removed and weighed after blood exsanguinations immediately.

\section{Statistical analysis}

Results were analyzed with Statistical Package for Social Sciences (SPSS 13.0 for Windows). Analysis of variance (ANOVA) was employed for analyzing all the data. A 5\% significance level $(\mathrm{P}<0.05)$ and two-tailed tests were used for all hypothesis tests.

\section{Results \\ Comparison of the serum levels of E2, FSH and LH}

In the MOD group, the serum levels of E2 were significantly lower, and the serum levels of FSH and LH were markedly higher than those of the RA group, EST group and SHAM group $(\mathrm{P}<0.05)$, which were shown as Figure 1 . As shown in Figure $1 \mathrm{~A}$ and $1 \mathrm{~B}$, in the RA group, the serum levels of E2 were significantly lower, and the serum levels of FSH were markedly higher than those of the SHAM group and EST group, respectively $(\mathrm{P}<0.05)$. There were no significant differences among RA group, EST group and SHAM group on the serum LH levels $(\mathrm{P}>0.05)$.

\section{Comparison of the serum levels of IL-2 and IL-8}

As shown in Figure 2, in the MOD group, the serum levels of IL-2 and IL-8 were significantly lower than those of the RA group, EST group and SHAM group $(\mathrm{P}<0.05)$, and no marked differences existed among RA group, EST group and SHAM group in the serum levels of IL-2 and IL-8 (P>0.05). 
Zheng et al., Afr J Tradit Complement Altern Med. (2013) 10(1):9-14

http://dx.doi.org/10.4314/ajtcam.v10i1.2

A

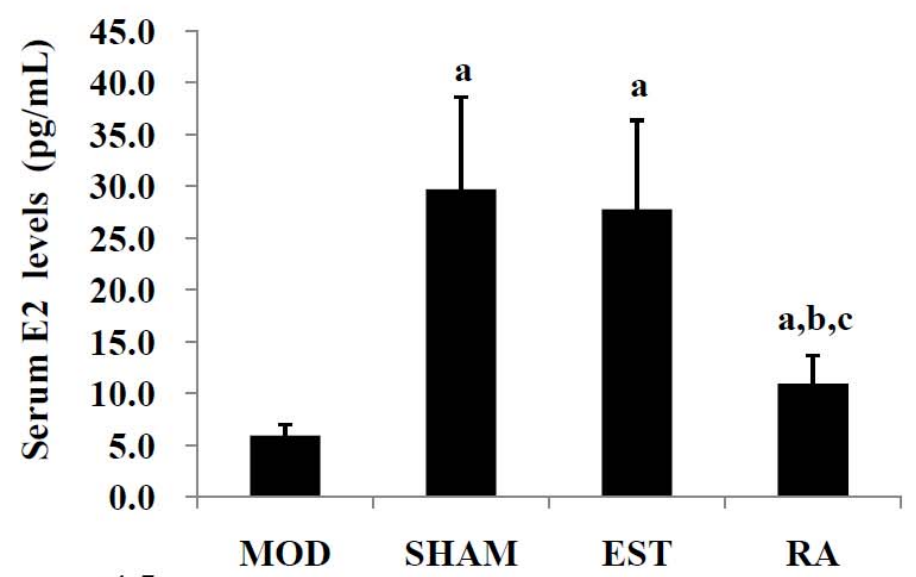

B

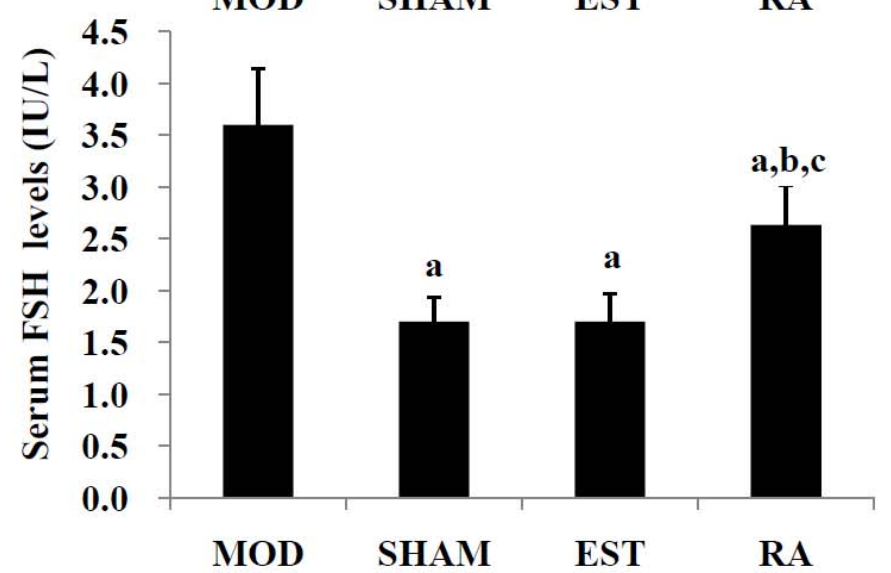

C

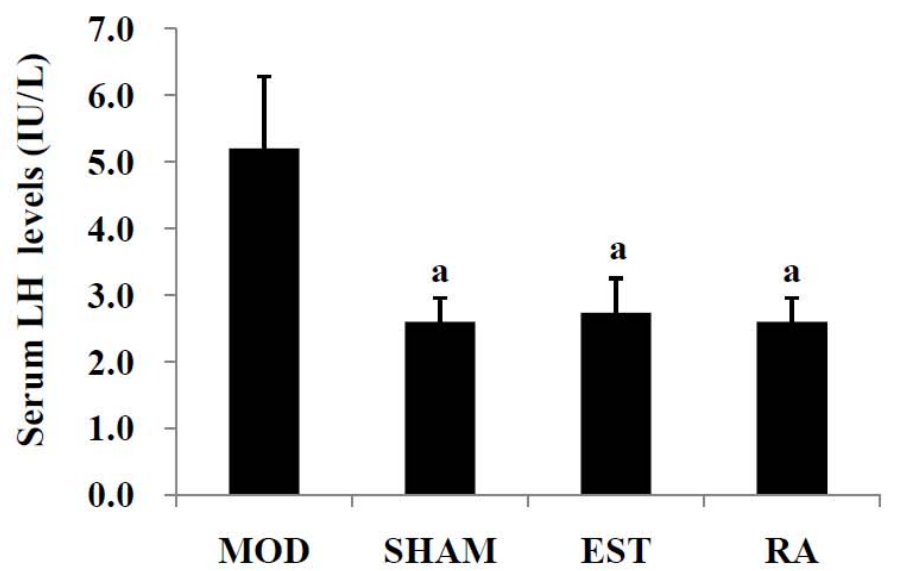

Figure 1: The serum levels of sex hormones. (A) The serum levels of estradiol (E2) of model control (MOD) group, sham-operation (SHAM) group, estrogen (EST) group and Radix Astragali (RA) group. (B) The serum levels of follicle stimulating hormone (FSH) of all the four groups. (C) The serum levels of luteinizing hormone (LH) of all the four groups. Data were shown as mean $\pm \mathrm{SD}$. ( $\mathrm{n}=6$ in each group). The significant difference was set at ${ }^{\mathrm{a}} \mathrm{P}<0.05$, compared with the MOD group; ${ }^{\mathrm{b}} \mathrm{p}<0.05$, compared with the SHAM group; ${ }^{\mathrm{c}} \mathrm{P}<0.05$, compared with the EST 
Zheng et al., Afr J Tradit Complement Altern Med. (2013) 10(1):9-14 http://dx.doi.org/10.4314/ajtcam.v10i1.2

group.

A

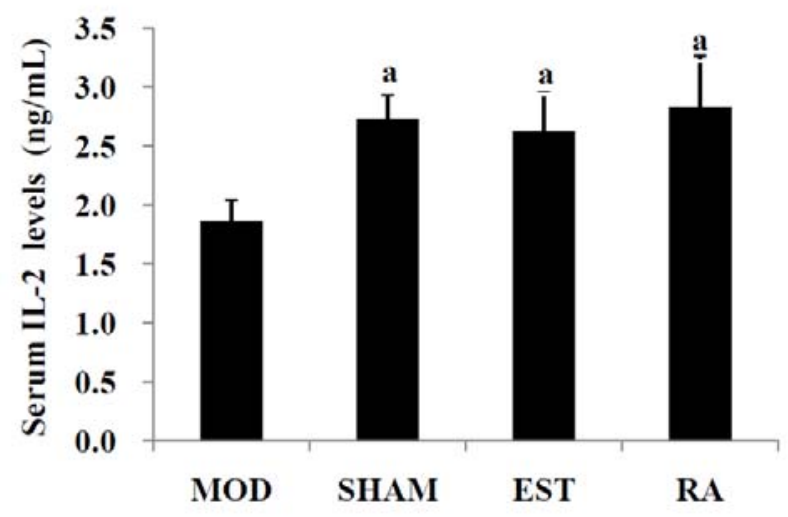

B

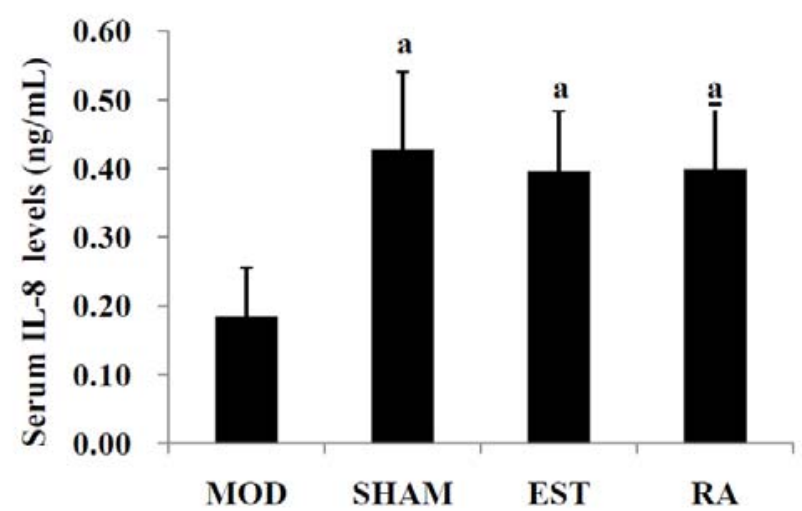

Figure. 2: The serum levels of interleukins (A) The serum levels of interleukin-2 (IL-2) of the four groups. (B) The serum levels of interleukin-8 (IL-8) of the four groups. Data were shown as mean \pm SD. ( $n=6$ in each group). The significant difference was set at ${ }^{\mathrm{a}} \mathrm{P}<0.05$, compared with the MOD group; ${ }^{\mathrm{b}} \mathrm{p}<0.05$, compared with the SHAM group; ${ }^{\mathrm{C}} \mathrm{P}<0.05$, compared with the EST group.

\section{Comparison of the uterine wet weight}

As shown in Figure 3, the uterine weight of the rats in the RA group, EST group and SHAM group were significantly higher than those of the rats in MOD group $(\mathrm{P}<0.05)$. There were no marked differences among the rats from RA group, EST group and SHAM group on the uterine wet weight $(\mathrm{P}>0.05)$.

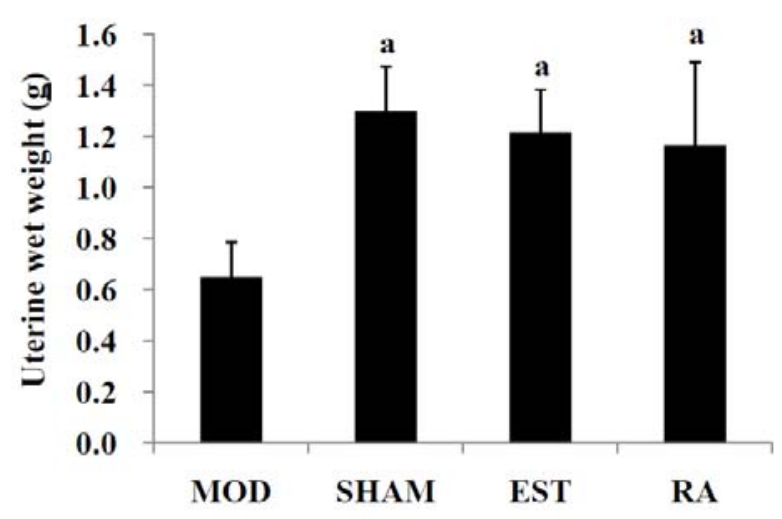


Zheng et al., Afr J Tradit Complement Altern Med. (2013) 10(1):9-14

http://dx.doi.org/10.4314/ajtcam.v10i1.2

Figure 3: Comparison of the uterine weight. Data were shown as mean \pm SD. ( $n=6$ in each group). The significant difference was set at ${ }^{\mathrm{a}} \mathrm{P}<0.05$, compared with the MOD group; ${ }^{\mathrm{b}} \mathrm{p}<0.05$, compared with the SHAM group; ${ }^{\mathrm{c}} \mathrm{P}<0.05$, compared with the EST group.

\section{Discussion}

Estrogen has been found to have both cognitive functions and neurobiological protective effects particularly when therapy is initiated close to the time of menopause before neural systems become increasingly compromised (Voytko et al., 2009). However, due to recent clinical trial negative results on hormone therapy, many postmenopausal women question whether to start or continue hormone therapy. Meanwhile, the market for complementary and alternative therapies for HRT has dramatically increased (Noguchi et al., 2009; Shou et al., 2011; Yeh and Chang, 2012). Women are seeking more natural alternatives to treat menopausal symptoms worldwide. We found in the present study that RA can improve the serum levels of IL-2 and IL-8 of the ovariectomized female rats as significantly as EST, although it did not alter the serum levels of E2, FSH and LH.

In recent years, more and more studies have focused on effects of HRT on the levels of immunoregulatory cytokines. A clinical investigation on previously healthy women who had undergone a total hysterectomy and bilateral salpingo-oopherectomy aiming to explore the effect of oral and transdermal estrogen replacement therapy on the expression of different estrogen receptor subtypes and the secretion of immunoregulatory cytokines found both oral and transdermal HRT can improve the balance of Th1/Th2 cytokines (Xia et al., 2009). Postmenopausal women without HRT were found to experience greater muscle damage, indicating a possible protective effect of HRT against exercise-induced skeletal muscle damage, during which mRNA expression of IL-6, IL-8 and IL-15 changed markedly in the control group compared with the HRT group (Dieli-Conwright et al., 2009). In a clinical trial to investigate the effects of HRT on immune function in menopausal women the researchers found significant alterations on the interleukin levels (Saucedo et al., 2002). Estrogen/progesterone HRT has been demonstrated to affect cell-mediated immunity, thus being a potential factor influencing development and course of autoimmune disorders and neoplastic diseases (Stopinska-Gluszak et al., 2006). Although RA did not change the sex hormones levels as significantly as estrogen did, we found RA can significantly improve the immune functions of the ovariectomized female rats, which merits further study. More study will be conducted on the effects of RA on the behavior of the ovariectomized female rats in the near future.

\section{Acknowledgements}

The present research was funded by the grants for young scientists of TCM, Zhejiang Province (No.2006Y004) and Analysis and testing grants from Science Technology Department of Zhejiang Province (No.2012C37005)

\section{References}

1. Borrelli, F., and Ernst, E. (2010). Alternative and complementary therapies for the menopause. Maturitas 66:333-343.

2. Carneiro, A.L., de Cassia de Maio Dardes, R., and Haidar, M.A. (2012). Estrogens plus raloxifene on endometrial safety and menopausal symptoms-semisystematic review. Menopause-the Journal of the North American Menopause Society 19:830-834.

3. Cioffi, M., Esposito, K., Vietri, M.T., Gazzerro, P., D'Auria, A., Ardovino, I., Puca, G.A., and Molinari, A.M. (2002). Cytokine pattern in postmenopause. Maturitas 41:187-192.

4. Dieli-Conwright, C.M., Spektor, T.M., Rice, J.C., Sattler, F.R., and Schroeder, E.T. (2009). Hormone therapy attenuates exercise-induced skeletal muscle damage in postmenopausal women. J Appl Physiol 107:853-858.

5. Duijts, S.F., Oldenburg, H.S., van Beurden, M., and Aaronson, N.K. (2009). Cognitive behavioral therapy and physical exercise for climacteric symptoms in breast cancer patients experiencing treatment-induced menopause: design of a multicenter trial. BMC Womens Health 9:15.

6. El-Bakri, N.K., Islam, A., Zhu, S., Elhassan, A., Mohammed, A., Winblad, B., and Adem, A. (2004). Effects of estrogen and progesterone treatment on rat hippocampal NMDA receptors: relationship to Morris water maze performance. J Cell Mol Med 8:537-544. 
Zheng et al., Afr J Tradit Complement Altern Med. (2013) 10(1):9-14

http://dx.doi.org/10.4314/ajtcam.v10i1.2

7. Kamada, M., Irahara, M., Maegawa, M., Ohmoto, Y., Murata, K., Yasui, T., Yamano, S., and Aono, T. (2001). Transient increase in the levels of T-helper 1 cytokines in postmenopausal women and the effects of hormone replacement therapy. Gynecol Obstet Invest 52:82-88.

8. Kessel, B., and Kronenberg, F. (2004). The role of complementary and alternative medicine in management of menopausal symptoms. Endocrinol Metab Clin North Am 33:717-739.

9. Kronenberg, F., and Fugh-Berman, A. (2002). Complementary and alternative medicine for menopausal symptoms: a review of randomized, controlled trials. Ann Intern Med 137:805-813.

10. Lloyd, K.B., and Hornsby, L.B. (2009). Complementary and alternative medications for women's health issues. Nutr Clin Pract 24:589-608.

11. Martin, K., Viera, K., Petr, C., Marie, N., and Eva, T. (2006). Simultaneous analysis of cytokines and co-stimulatory molecules concentrations by ELISA technique and of probabilities of measurable concentrations of interleukins IL-2, IL-4, IL-5, IL-6, CXCL8 (IL-8), IL-10, IL-13 occurring in plasma of healthy blood donors. Mediators Inflamm 2006:65237.

12. Mazaro-Costa, R., Andersen, M.L., Hachul, H., and Tufik, S. (2010). Medicinal Plants as Alternative Treatments for Female Sexual Dysfunction: Utopian Vision or Possible Treatment in Climacteric Women? J Sex Med 7:3695-3714.

13. Miquel, J., Ramirez-Bosca, A., Ramirez-Bosca, J.V., and Alperi, J.D. (2006). Menopause: A review on the role of oxygen stress and favorable effects of dietary antioxidants. Arch Geron Geria 42:289-306.

14. Noguchi, M., Yuzurihara, M., Ikarashi, Y., Tsuchiya, N., Hibino, T., Mase, A., and Kase, Y. (2009). Effects of the traditional Japanese medicine Tokaku-jyoki-to in rat-models for menopausal hot flash. J Ethnopharmacol 126:96-101.

15. Roberts, H. (2012). Hormone therapy for menopausal symptoms. BMJ 344:e815.

16. Saucedo, R., Rico, G., Basurto, L., Ochoa, R., and Zarate, A. (2002). Transdermal estradiol in menopausal women depresses interleukin-6 without affecting other markers of immune response. Gynecol Obstet Invest 53:114-117.

17. Seidl, M.M., and Stewart, D.E. (1998). Alternative treatments for menopausal symptoms. Systematic review of scientific and lay literature. Can Fam Physician 44:1299-1308.

18. Shou, C., Li, J., and Liu, Z. (2011). Complementary and alternative medicine in the treatment of menopausal symptoms. Chin J Integr Med 17:883-888.

19. Stopinska-Gluszak, U., Waligora, J., Grzela, T., Gluszak, M., Jozwiak, J., Radomski, D., Roszkowski, P.I., and Malejczyk, J. (2006). Effect of estrogen/progesterone hormone replacement therapy on natural killer cell cytotoxicity and immunoregulatory cytokine release by peripheral blood mononuclear cells of postmenopausal women. J Reprod Immunol 69:65-75

20. Voytko, M.L., Tinkler, G.P., Browne, C., and Tobin, J.R. (2009). Neuroprotective effects of estrogen therapy for cognitive and neurobiological profiles of monkey models of menopause. Am J Primatol 71:794-801.

21. WHO. http://apps.who.int/medicinedocs/en/d/Js2200e/7.html\#Js2200e.7.

22. Xia, X., Zhang, S., Yu, Y., Zhao, N., Liu, R., Liu, K., and Chen, X. (2009). Effects of estrogen replacement therapy on estrogen receptor expression and immunoregulatory cytokine secretion in surgically induced menopausal women. J Reprod Immunol 81:89-96.

23. Yeh, S.C., and Chang, M.Y. (2012). The Effect of Qigong on Menopausal Symptoms and Quality of Sleep for Perimenopausal Women: A Preliminary Observational Study. J Altern Complement Med 